\title{
Long-term stability of species composition in calanoid copepods off southern California
}

\author{
Ginger A. Rebstock* \\ Scripps Institution of Oceanography, University of California, San Diego, 9500 Gilman Drive 0218, La Jolla, \\ California 92093-0218, USA
}

\begin{abstract}
The stability of the species composition of calanoid copepods was investigated off southern California using samples collected during spring by the California Cooperative Oceanic Fisheries Investigations (CalCOFI) from 1951 through 1999. The region was consistently dominated in spring by 3 species, Calanus pacificus, Metridia pacifica and Pleuromamma borealis, which together accounted for $77 \%$ of the total on average. Four other categories each usually accounted for 3 to $7 \%$ of the total, but were occasionally much more abundant. All other species each generally made up less than $1 \%$ of the total. Species composition was compared between pairs of cruises using the percent similarity index (PSI). Species composition was found to be stable over the 49 yr covered by the study. Mean PSI values for each cruise were consistently high, except for 6 anomalous years, 1951, 1977, 1978, 1983, 1992 and 1998. The increased frequency of anomalous years following the 1976/1977 climatic regime shift, rather than an overall decline in similarity, may account for the difference in PSI means before and after the regime shift. Of the 6 anomalous cruises, 3 coincided with strong California El Niño events during the warm-water period of the 1980s and 1990s, while 2 occurred immediately after the 1976/1977 regime shift.
\end{abstract}

KEY WORDS: Species composition - Stability $\cdot$ Percent similarity index $\cdot$ Copepoda $\cdot$ Calanoida California Current System

Resale or republication not permitted without written consent of the publisher

\section{INTRODUCTION}

Species composition, that is, the relative abundances of species, is an important aspect of community or ecosystem ecology. How that composition varies over time, or the stability of the system, is another important concept. A stable system is one that remains at or returns to some kind of equilibrium (which may involve fluctuations within limits) when a disturbing force is applied (Connell \& Sousa 1983). Disturbance and perturbation are key aspects of stability. Disturbance is usually defined as a force or mechanism that acts on a system and potentially perturbs it. Disturbance is often equated with environmental variability, especially aperiodic or episodic variability (e.g., Floder \&

*E-mail: grebstock@ucsd.edu
Sommer 1999). McGowan (1990) defined disturbance as 'a significant and anomalous departure from the longterm mean conditions'. A perturbation is a response of a population or community to a disturbance. It may be detected as a significant change in a variable of the system, such as biomass or relative abundance (Connell \& Sousa 1983).

The California Current System (CCS) has been described as highly variable, with little stability in planktonic communities. For example, McGowan \& Walker (1985) reported low similarity of copepod species composition between samples collected in the CCS. Venrick (1990) analyzed 20 yr of diatom data collected by W. E. Allen from the Scripps Pier, La Jolla, California, and found 'no stability on any time scale' from weeks to years. However, Moser \& Smith (1993) found recurrent groups of larval fish that persisted over decades in the CCS. 
In contrast, the central gyre of the North Pacific Ocean has been found to be a very stable system in terms of planktonic species composition. McGowan \& Walker (1985) found little difference in copepod species composition between samples taken years apart. Venrick (1990) reached similar conclusions for the phytoplankton, finding only small, nondirectional differences in species composition over more than a decade of sampling.

The stability of species composition of marine plankton has been investigated in a few other systems, with mixed results. Seasonal succession patterns of copepods remained similar over almost $70 \mathrm{yr}$ in spite of environmental changes in the northwest Atlantic Ocean (Sherman et al. 1983). During the strong El Niño of 1983/1984, the usual seasonal succession of copepods was disrupted off Oregon (Miller et al. 1985), but not in a bay in southern Baja California, Mexico (Palomares-Garcia \& Gomez-Gutierrez 1996).

Several long-term studies have found changes in planktonic species composition over time. In the North Sea and northeastern Atlantic Ocean, sampling by the Continuous Plankton Recorder (CPR) program has indicated changes in dominance structure of the plankton (Reid 1975, 1977, CPR Survey Team 1992, Lindley et al. 1995). Valdes \& Moral (1998) documented a decrease in species richness and diversity among the copepods in the Bay of Biscay over 5 yr.

The Russell Cycle in the western English Channel provides one of the clearest examples of changes in planktonic community structure (Southward 1980). The system switched between 2 different zooplankton communities in the 1930s, then switched back in the 1970s. This does not necessarily indicate lack of stability in the plankton, since each assemblage persisted for a period of time and the environment differed between phases of the cycle.

Physical states in the CCS are also known to vary, on several time scales. The El Niño-Southern Oscillation (ENSO) cycle strongly influences the northeastern Pacific Ocean on interannual time scales. Physical effects of El Niño in the CCS include decreased upwelling, reduced equatorward flow, increased nearsurface temperatures, a deepening of the thermocline, and a rise in coastal sea level (Murphree \& Reynolds 1995). Biological effects of El Niño in the CCS are varied and poorly understood. Primary productivity often decreases and the onset of the spring bloom may be delayed (Lenarz et al. 1995). Range extensions or contractions are often seen in fishes (Lenarz et al. 1995) and zooplankton (Roesler \& Chelton 1987). Zooplankton volumes decline, and survival and growth of some fish stocks are adversely affected (Lenarz et al. 1995). Mullin (1998) found declines of 58 to $91 \%$ in abundance of Calanus pacificus off southern Cali- fornia during El Niño events. The zooplankton off southern California shifted from a thaliacean-dominated assemblage to one dominated by copepods during the 1957 to 1959 El Niño. Most of the major zooplankton taxa declined by 30 to $96 \%$ during this period (Smith 1985).

Decadal-scale climate variability also affects the CCS (e.g., Miller et al. 1994b, Minobe \& Mantua 1999). Transitions between phases of decadal-scale cycles may be fairly abrupt, such as the 1976/1977 Pacific climate regime shift. At this time, the Aleutian Low intensified, resulting in changes in North Pacific storm tracks and intensity. Surface waters in the central North Pacific cooled, while those in the CCS warmed (Miller et al. 1994a). This regime shift shows up in time series of several climate indices as a transition between multiyear periods of fairly stable means (Beamish et al. 1999). Many biological as well as physical variables apparently responded to this shift (Ebbesmeyer et al. 1991). Another regime shift (but not back to pre-1976 conditions) may have occurred around 1990 (Beamish et al. 1999).

The goal of this study was to describe patterns in the species composition of calanoid copepods in the southern California region of the CCS over $49 \mathrm{yr}$. Stability of dominance structure has been examined for spring cruises. The major focus is on broad spatial averages and long-term patterns. However, withincruise data are also presented for 7 cruises, spanning hours to weeks and tens to hundreds of kilometers. Interdecadal regime shifts and the ENSO cycle are investigated as potential disturbing forces.

\section{METHODS}

The zooplankton samples analyzed for this study were collected by the California Cooperative Oceanic Fisheries Investigations (CalCOFI). Samples from 41 spring (April, March or May) cruises from 1951 through 1999, collected at night off southern California, were analyzed (Table 1, Fig. 1A). Replicate samples collected in the winter and summer of 1975 off central California and northern Baja California, Mexico, were included to provide estimates of maximum expected similarity (Fig. 1B). These samples were collected in a series of net tows while the ship followed a drogue. Samples collected in a given series are considered to be replicates, since, in principle, the ship followed the same water parcel as it followed the drogue.

Samples were collected and preserved using standard CalCOFI protocols (Kramer et al. 1972, Ohman \& Smith 1995). All nets were towed obliquely between the surface and approximately $140 \mathrm{~m}$ (1951 to 1966) or $212 \mathrm{~m}$ (1969 to 1999). Two different net types were 
Table 1. Date ranges for samples from spring cruises and number of stations pooled for each cruise. Cruise number $=$ year and month (YYMM)

\begin{tabular}{|c|c|c|c|}
\hline Cruise & Start date & End date & No. of stations \\
\hline 5104 & 8 Apr 1951 & 16 Apr 1951 & 8 \\
\hline 5204 & 1 Apr 1952 & 13 Apr 1952 & 10 \\
\hline 5304 & 7 Apr 1953 & 30 Apr 1953 & 11 \\
\hline 5404 & 7 Apr 1954 & 19 Apr 1954 & 14 \\
\hline 5504 & 7 Apr 1955 & 15 Apr 1955 & 8 \\
\hline 5604 & 15 Apr 1956 & 21 Apr 1956 & 8 \\
\hline 5704 & 12 Apr 1957 & 19 Apr 1957 & 8 \\
\hline 5804 & 1 Apr 1958 & 19 Apr 1958 & 8 \\
\hline 5904 & 12 Apr 1959 & 23 Apr 1959 & 12 \\
\hline 6004 & 29 Mar 1960 & 8 Apr 1960 & 15 \\
\hline 6104 & 8 Apr 1961 & 25 Apr 1961 & 13 \\
\hline 6204 & 17 Mar 1962 & 15 Apr 1962 & 18 \\
\hline 6304 & 12 Apr 1963 & 2 May 1963 & 10 \\
\hline 6404 & 10 Apr 1964 & 21 Apr 1964 & 12 \\
\hline 6504 & 1 Apr 1965 & 9 Apr 1965 & 14 \\
\hline 6604 & 29 Mar 1966 & 2 May 1966 & 17 \\
\hline 6904 & 4 Apr 1969 & 13 Apr 1969 & 11 \\
\hline 7203 & 13 Mar 1972 & 21 Mar 1972 & 11 \\
\hline 7505 & 13 May 1975 & 25 May 1975 & 14 \\
\hline 7603 & 28 Mar 1976 & 1 Apr 1976 & 10 \\
\hline 7703 & 8 Mar 1977 & 21 Mar 1977 & 10 \\
\hline 7804 & 29 Mar 1978 & 15 Apr 1978 & 12 \\
\hline 7904 & 6 Apr 1979 & 16 Apr 1979 & 9 \\
\hline 8004 & 13 Apr 1980 & 28 Apr 1980 & 7 \\
\hline 8104 & 7 Apr 1981 & 19 Apr 1981 & 12 \\
\hline 8203 & 15 Mar 1982 & 1 Apr 1982 & 9 \\
\hline 8303 & 19 Mar 1983 & 28 Mar 1983 & 13 \\
\hline 8505 & 1 May 1985 & 17 May 1985 & 11 \\
\hline 8605 & 9 May 1986 & 18 May 1986 & 11 \\
\hline 8705 & 30 Apr 1987 & 11 May 1987 & 14 \\
\hline 8805 & 28 Apr 1988 & 10 May 1988 & 12 \\
\hline 8904 & 17 Apr 1989 & 28 Apr 1989 & 9 \\
\hline 9004 & 18 Apr 1990 & 28 Apr 1990 & 13 \\
\hline 9204 & 13 Apr 1992 & 28 Apr 1992 & 11 \\
\hline 9304 & 30 Mar 1993 & 11 Apr 1993 & 10 \\
\hline 9403 & 22 Mar 1994 & 4 Apr 1994 & 15 \\
\hline 9504 & 6 Apr 1995 & 18 Apr 1995 & 13 \\
\hline 9604 & 15 Apr 1996 & 28 Apr 1996 & 12 \\
\hline 9704 & 2 Apr 1997 & 16 Apr 1997 & 8 \\
\hline 9804 & 2 Apr 1998 & 15 Apr 1998 & 13 \\
\hline 9904 & 1 Apr 1999 & 13 Apr 1999 & 12 \\
\hline
\end{tabular}

used, both with a mesh size of about $0.5 \mathrm{~mm}$. From 1951 through 1976, a 1 m diameter ring net was used. In 1977, the ring net was replaced with a bongo net (McGowan \& Brown 1966) of $0.6 \mathrm{~m}$ diameter (1977) or $0.71 \mathrm{~m}$ diameter (since 1978). Potential biases due to methodological changes are discussed below. For CalCOFI tows, the bongo net is towed open and the sample from only 1 side is used. Samples were preserved in buffered formalin and seawater and archived in the 'Pelagic Invertebrates Collection' of Scripps Institution of Oceanography.

Thirty-three categories of calanoid copepod were enumerated (Table 2). Adult females of 30 species or subspecies were counted by category. All other adult
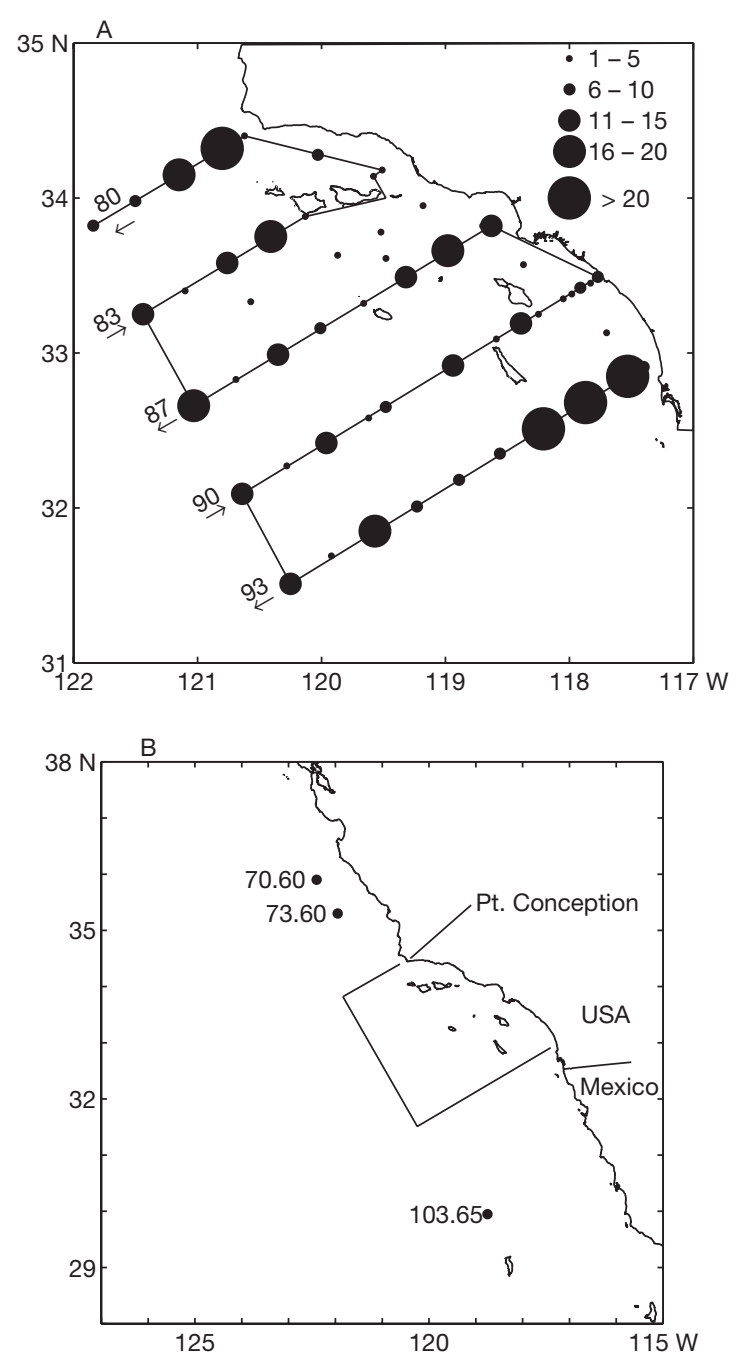

Fig. 1. (A) Station locations and sampling frequency for spring cruises; standard CalCOFI lines are numbered at offshore end of line; arrows indicate direction of travel on standard lines; size of dots is proportional to the number of times a sample was used from each station; several nonstandard stations were also used in this study (dots off lines). (B) Station locations for replicate tows; first tow for each station began at locations indicated, but ship followed a drogue for the remaining tows; Stn 73.60 was sampled in February 1975 (5 replicate tows); Stns 70.60 (4 replicates) and 103.65 (5 replicates) were sampled in June or July 1975. Box outlines location of study region for spring samples

female calanoid copepods with total length greater than about $1.5 \mathrm{~mm}$ were counted, but not identified, and combined in the 'other female calanoids' category. For Neocalanus cristatus and N. plumchrus, only Stage 5 copepodites were counted because the adults do not occur in the upper $200 \mathrm{~m}$ of the water column (Conover 1988). These 2 species were included as indicators of subarctic water.

Samples within spring cruises were pooled prior to counting, except that 1 cruise per decade was ana- 
Table 2. Calanoid copepod categories enumerated. Only adult females were counted, except for Neocalanus plumchrus and $N$. cristatus (see 'Methods'). Sorted by mean percent dominance

\begin{tabular}{|c|c|c|c|}
\hline \multirow{2}{*}{ Category } & \multicolumn{3}{|c|}{ Percent dominance } \\
\hline & Mean & Min. & Max. \\
\hline Calanus pacificus Brodsky & 33.92 & 4.31 & 66.44 \\
\hline Metridia pacifica Brodsky & 28.49 & 2.71 & 77.77 \\
\hline Pleuromamma borealis (Dahl) & 14.55 & 0.74 & 51.04 \\
\hline Other female calanoids & 7.02 & 2.32 & 22.99 \\
\hline Eucalanus californicus Johnson & 4.46 & 0.17 & 25.49 \\
\hline Rhincalanus nasutus Giesbrecht & 3.69 & 0.06 & 16.51 \\
\hline $\begin{array}{l}\text { Pleuromamma abdominalis edentata } \\
\text { (Lubbock) }\end{array}$ & 2.73 & 0.70 & 6.23 \\
\hline Pleuromamma gracilis (Claus) & 1.03 & 0.07 & 4.54 \\
\hline Mesocalanus tenuicornis (Dana) & 0.97 & 0.11 & 2.69 \\
\hline Heterorhabdus papilliger (Claus) & 0.41 & 0.05 & 1.35 \\
\hline Pleuromamma quadrungulata (Dahl) & 0.35 & 0.00 & 1.02 \\
\hline Candacia bipinnata Giesbrecht & 0.30 & 0.00 & 0.85 \\
\hline Aetideus bradyi Scott & 0.29 & 0.00 & 1.52 \\
\hline Euchirella pseudopulchra Park & 0.24 & 0.03 & 1.24 \\
\hline Euchaeta media Giesbrecht & 0.24 & 0.00 & 1.24 \\
\hline Labidocera trispinosa Esterly & 0.19 & 0.00 & 3.43 \\
\hline Pleuromamma abdominalis typica & 0.17 & 0.00 & 0.59 \\
\hline Candacia curta (Dana) & 0.15 & 0.00 & 1.07 \\
\hline Pleuromamma piseki Farran & 0.15 & 0.00 & 1.03 \\
\hline Nannocalanus minor (Claus) & 0.14 & 0.00 & 1.39 \\
\hline Lucicutia flavicornis (Claus) B & 0.13 & 0.00 & 0.82 \\
\hline Pleuromamma xiphias (Giesbrecht) & 0.09 & 0.00 & 0.41 \\
\hline Lucicutia flavicornis (Claus) A & 0.08 & 0.00 & 0.33 \\
\hline Neocalanus gracilis (Dana) & 0.06 & 0.00 & 1.12 \\
\hline Eucalanus hyalinus (Claus) & 0.06 & 0.00 & 0.19 \\
\hline Neocalanus plumchrus (Marukawa) CV & 0.03 & 0.00 & 0.48 \\
\hline Heterorhabdus abyssalis (Giesbrecht) & 0.03 & 0.00 & 0.19 \\
\hline Eucalanus attenuatus (Dana) & 0.02 & 0.00 & 0.31 \\
\hline Candacia aethiopica (Dana) & 0.01 & 0.00 & 0.31 \\
\hline Neocalanus robustior (Giesbrecht) & 0.01 & 0.00 & 0.12 \\
\hline Mesocalanus lighti (Bowman) & 0.01 & 0.00 & 0.11 \\
\hline Neocalanus cristatus (Krøyer) CV & 0.003 & 0.00 & 0.12 \\
\hline Euchaeta rimana Bradford & 0.002 & 0.00 & 0.08 \\
\hline
\end{tabular}

lyzed by station to obtain estimates of the variance among stations. For each cruise, all samples collected at night ( $1 \mathrm{~h}$ after sunset until $1 \mathrm{~h}$ before sunrise) within the southern California study region (Fig. 1A) were selected. Stations shallower than the nominal depth of 140 or $212 \mathrm{~m}$ were omitted. Seven to 18 stations $($ mean $=11.8)$ were selected for each cruise. Prior to pooling, large organisms (>25 $\mathrm{mm}$ total length) were removed from the samples. Aliquots representing a standard volume of water filtered (usually $50 \mathrm{~m}^{3}$ ) were removed from each sample with a Stempel pipette. These aliquots were combined into a pooled sample for each cruise; $20 \%$ of each pooled sample was counted; 2 to $50 \%$ of each nonpooled sample was analyzed.

All counts were standardized to unit area of sea surface, using the volume filtered and depth of the samples. For pooled samples, the total volume filtered of the pooled aliquots and the mean depth of the stations were used.
Species composition between pairs of samples was compared using the percent similarity index (PSI: Whittaker 1952, Whittaker \& Fairbanks 1958):

$$
\text { PSI }=100-0.5 \sum\left|A_{i}-B_{i}\right|=\sum \min \left(A_{i}, B_{i}\right),
$$

where $A_{i}, B_{i}=$ the percentages of species $i$ in samples $A$ and $B$, respectively.

PSI is strongly influenced by the most abundant species. Since most cruises were dominated by a few categories (see 'Results'), an index that gives high importance to the dominant species was considered appropriate. In addition, many of the rare species did not show a consistent rank order of abundance, perhaps due to less accurate estimates of density in the species that were represented by only a few individuals per sample.

PSI was calculated for 5 types of comparisons: (1) between all pairs of spring cruises (using the calculated mean density of each species for cruises that were not pooled), giving intervals of 1 to $48 \mathrm{yr}$ (2) between all pairs of stations within each spring cruise in which stations were not pooled, giving intervals of about $1 \mathrm{~h}$ to $16 \mathrm{~d}$, and tens of kilometers to $>500 \mathrm{~km}$; (3) between all pairs of cruises for each station that was sampled and analyzed individually more than once, giving intervals of 5 to $44 \mathrm{yr}$; (4) between all pairs of replicate tows in the winter and summer 1975 samples and between the 2 stations sampled during the summer 1975 cruise; (5) between all pairs of aliquots from 4 pooled samples (Cruises 5704, 7505, 8004 and 9204).

To test for trends in PSI over time or distance, leastsquares linear regression lines were fit for the first 3 types of comparisons, with PSI as the dependent variable and time interval or distance between samples as the independent variable. Since the residuals from the linear regressions are not normally distributed and the pairwise comparisons are not all independent, a randomization test was used to determine if the slope of the regression line differs significantly from zero. PSI values were randomly resampled 5000 times, without replacement, keeping the number of points per time or distance interval constant. That is, PSI $(y)$ values were randomly reassigned to the interval $(x)$ values. The slopes of the regression lines from the iterations form an empirical distribution from which probability levels can be obtained.

The coastal sea level at San Diego, California, was used as a local indicator of El Niño. Monthly mean values were obtained from the 'University of Hawaii Sea Level Center (UHSLC)' web site (uhslc.soest.hawaii.edu/uhslc/ datai.html). A 5 mo running mean was calculated for the standardized anomalies after removal of seasonal cycles and a linear trend. Any period in which the running mean exceeded 1 standard deviation for at least 5 mo was considered to be an El Niño. Only 4 California El Niños were identified by this method: 1958/1959, 1983, 1992/1993 and 1998. All these events were also 
tropical El Niños, using the definition of Trenberth (1997). In some cases, such as 1959, a high coastal sea level in southern California persisted longer than El Niño conditions in the equatorial Pacific.

Means of PSI values for cruises before and after the 1976/1977 climatic regime shift were compared using a randomization procedure. PSI values for comparisons between the periods 1951 to 1976 and 1977 to 1999 ('between') were compared with PSI values within 1951 to 1976 and within 1977 to 1999 ('within'). The PSI values were randomly assigned to the categories (between or within). The difference between the means of the 2 categories was calculated for each of 5000 iterations, forming an empirical distribution for determining probability levels. A similar test was done to determine if a hypothesized regime shift in the North Pacific around 1989 (e.g., Beamish et al. 1999, Brodeur et al. 1999, Overland et al. 1999) affected species composition.

As indicated above, several sampling method changes have been made over the $50 \mathrm{yr}$ of the CalCOFI program. Two of the changes could affect the time series of copepod densities and hence the analysis of species composition stability over time: (1) the increase in depth of tow from 140 to $212 \mathrm{~m}$ in 1969, and (2) the replacement of the $1 \mathrm{~m}$ ring net with the bongo net in 1977. Paired samples were collected with the 2 net types in 1975 and 1978 for the purpose of comparing their performance. Many of those samples were analyzed for differences in calanoid copepod-density estimates (Rebstock 2001). No evidence of any gear bias was found, although the results were not always conclusive due to low statistical power. Based on these comparisons, it is assumed that the change in net type did not have a significant effect on the species composition of the calanoid copepods sampled.

Unfortunately, no paired samples exist for comparison of the 2 sampling depth intervals. Many of the species enumerated, especially the dominant species, occur primarily in the upper 100 to $150 \mathrm{~m}$ of the water column at night, so the increase in sampling depth should have had little effect on the estimated densities for those species. However, large proportions of some of the species do occur between 140 and $212 \mathrm{~m}$ at night. An apparent increase in density would be expected starting in 1969 for those species. In fact, such an apparent increase is seen for several species, particularly Heterorhabdus abyssalis, Lucicutia flavicornis B, Pleuromamma gracilis, $P$. piseki, P. quadrungulata, Euchaeta media, 'other female calanoids' and possibly Rhincalanus nasutus (Rebstock unpubl. data).

In order to determine whether the apparent increases in density affected the results of this study, the densities of the categories listed above were adjusted to remove the median difference between the periods 1951 to 1966 and 1969 to 1999. PSI was calculated between all pairs of spring cruises using the adjusted and unadjusted densities. There were no apparent changes in the patterns of the PSI time series. However, the adjustment did affect the slope of the regression lines for PSI as a function of time interval for the spring cruises (see 'Results').

\section{RESULTS}

The calanoid copepod assemblage off southern California in spring was consistently dominated by a few species (Table 2, Fig. 2). In the pooled samples, Calanus pacificus, Metridia pacifica and Pleuromamma borealis together accounted for a mean of $77 \%$ (range: 40 to $91.4 \%$ ) of the adult female calanoid copepods with total length $\geq 1.5 \mathrm{~mm}$. Only 4 other categories ever accounted for more than $5 \%$ of the total: Eucalanus californicus, Rhincalanus nasutus, $P$. abdominalis edentata and 'other female calanoids' (but see notes in following paragraph on Aetideus divergens). These 7 categories made up $95 \%$ of the total on average. $C$. pacificus and $M$. pacifica were consistently dominant, accounting for less than $5 \%$ of the total in only 1 and 2 cruises, respectively. $P$. borealis accounted for less than $5 \%$ in 7 cruises, and less than $1 \%$ in 1 cruise.

Aetideus divergens Bradford was included in the 'other female calanoids' category for calculating PSI, but was also counted separately in a few cruises when it was exceptionally abundant. In 1977 this species ranked third, and accounted for $11.7 \%$ of the total. It

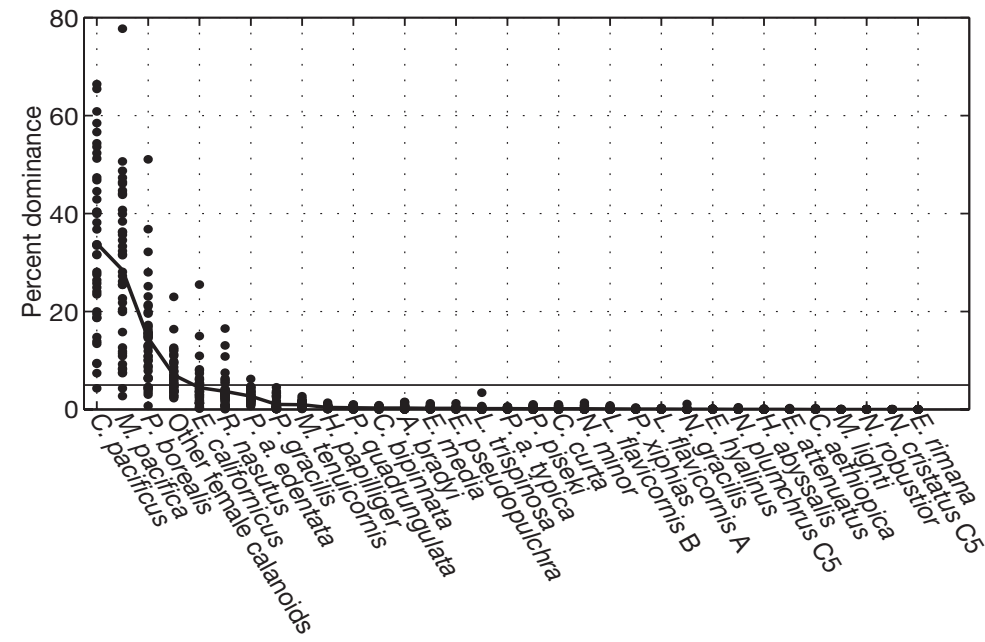

Fig. 2. Percent dominance by species or category for spring cruises, sorted by mean percent dominance. Curve connects mean percentages. Each column of dots represents the percentage contribution to the total for that category in the 41 spring cruises. The solid horizontal line marks $5 \%$. Full specific names are given in Table 2 
accounted for between 3 and $6 \%$ of the total in 4 other years: 1969, 1972, 1988 and 1994. This was the only species which was usually rare (or absent) that was ever among the dominant species. However, it is a fairly small copepod $(<2 \mathrm{~mm})$ and may not have been sampled quantitatively by the nets. Factors such as degree of clogging of the nets may have contributed to the apparent abundance pattern.

For comparisons between pairs of aliquots within pooled cruise samples, PSI values ranged from 70.5 to $93.8 \%$ (Fig. 3). For the comparisons between pairs of replicate tows (Fig. 3), PSI values were similar to the between-aliquot comparisons, 74.0 to $92.5 \%$. The comparisons between aliquots and between replicate tows, representing the same sample or water mass, should give some indication of the subsampling or sampling error, respectively. Based on these comparisons then, subsampling and sampling error may reduce the maximum PSI by as much as $20 \%$.

The 2 stations that were sampled 4 to 5 times each during Cruise 7507 (Stns 70.60 and 103.65) were compared with each other for contrast with the shorter distances between stations within the study region. The PSI values were the lowest seen in this study (Fig. 3), ranging from 7.9 to $30.0 \%$, with a mean of $18.4 \%$. These 2 stations had the largest distance interval $(\sim 740 \mathrm{~km})$ between any sample pair in the study. The 2 stations did have a number of species in common, but the dominance structure was very dissimilar.

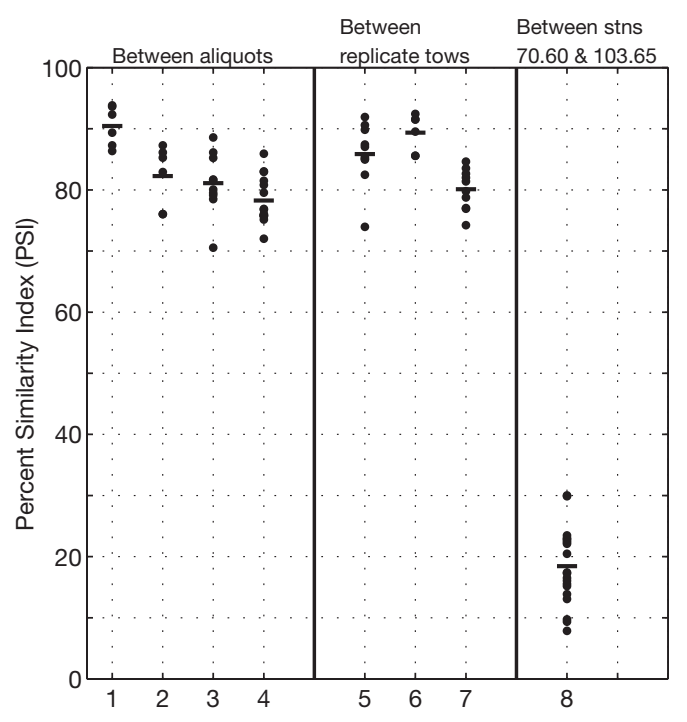

Fig. 3. PSI between aliquots and between replicate tows. PSI values and mean (horizontal lines) are given for each set of comparisons. 1-4: comparisons between aliquots within pooled samples $(1=$ Cruise 5704, $2=$ Cruise 7505, $3=$ Cruise 8004, $4=$ Cruise 9204); 5-7: comparisons between replicate tows within station ( $5=$ Cruise 7501, Stn 73.60; $6=$ Cruise 7507, Stn 70.60; $7=$ Cruise 7507, Stn 103.65); 8: comparisons between Stns 70.60 (4 replicate tows) and 103.65 (5 replicate tows), Cruise 7507
PSI as a function of time interval between pairs of spring cruises is plotted in Fig. 4. The slope of the regression line (Fig. 4A) was significantly different from zero $(p=0.0012)$. However the linear trend explains very little of the variance $\left(r^{2}=0.01\right)$, and PSI values for the longest intervals were generally within the range of those for the shortest intervals. High values, comparable to the values for the comparisons between aliquots and between replicate tows, were found for nearly all intervals, including some in excess of $45 \mathrm{yr}$. Copepod densities were adjusted to remove the median differences between the periods 1951 to 1966 and 1969 to 1999 for the 8 species that showed apparent increases in abundance in 1969 when the sampling depth increased (see 'Methods'). The slope decreased to -0.07 , and was no longer significant $(p=0.12)$. The decline in PSI over time may be an artifact of the increase in sampling depth in 1969.

Where samples from individual stations were analyzed for more than 1 cruise, between-cruise PSI values were calculated for each station (Fig. 4B). PSI values tended to be low compared to the values for the cruises in which samples were pooled (Fig. 4A). The slope was not significantly different from zero $(p=0.32)$. Although the
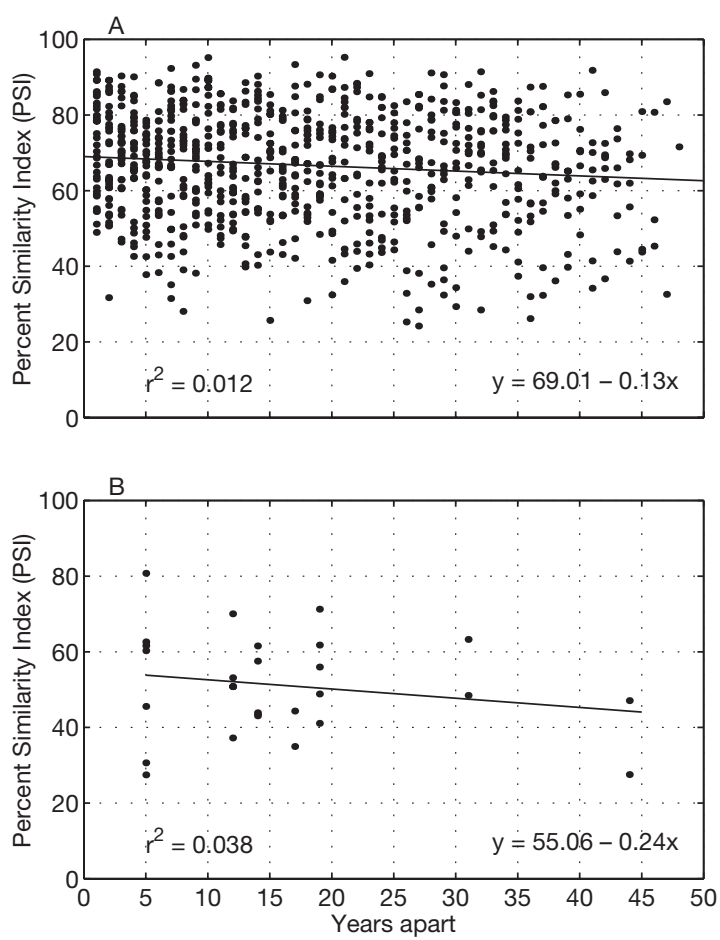

Fig. 4. PSI as a function of time interval between samples. Dots in the first column represent pairs of samples that were taken 1 yr apart, those in the second column, samples that were taken 2 yr apart, etc. Lines are least-squares linear regressions. (A) PSI for spring cruises (pooled samples); (B) between-cruise PSI values for stations that were analyzed individually 
values for the longest interval were relatively low, they were within the range of those for the shortest interval.

For comparisons within cruises (between stations), PSI values are plotted as a function of distance rather than time because of the nature of the sampling grid (Fig. 1A). The first station sampled on 1 line and the last station sampled on the next line are close in distance, but more widely separated in time than some more distant stations. PSI declined significantly with distance in 3 of the 5 cruises: 7804, 8303 and 9504 (Fig. 5, Table 3).

A time series of PSI for the 41 spring cruises was constructed by plotting year on the $x$-axis and the PSI values from all 40 comparisons for each year on the $y$-axis (Fig. 6). The time series shows a large amount of scatter, with an overall range of $71 \%$. The median range for the cruises is $50 \%$. However, when the mean PSI values for each year are calculated, a pattern is evident (Fig. 6). The time series shows several anomalous years in species composition, that is, years that were relatively dissimilar to most other years. Annual mean PSI was less than $60 \%$ in only 6 years: 1951, 1977, 1978, 1983, 1992 and 1998.
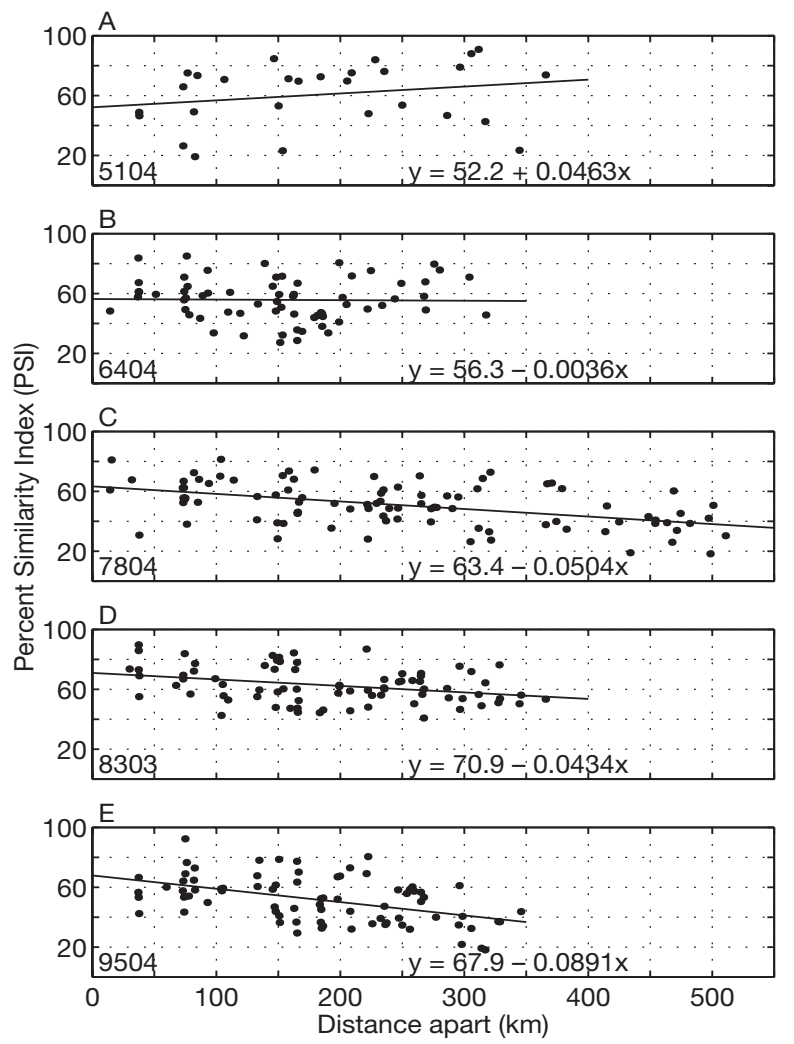

Fig. 5. PSI as a function of distance for within-cruise (between-station) comparisons. Least-squares linear regression lines and equations are shown. (A) Cruise 5104, 8 stations, 28 pairwise comparisons; (B) Cruise 6404, 12 stations, 66 comparisons; (C) Cruise 7804, 14 stations, 91 comparisons; (D) Cruise 8303, 13 stations, 78 comparisons; (E) Cruise 9504, 13 stations, 78 comparisons
Table 3. Linear regression statistics for percent similarity index (PSI) as a function of distance between stations, for the 5 cruises analyzed by station. Probability based on randomization tests (5000 iterations)

\begin{tabular}{|c|c|c|c|c|c|}
\hline Cruise & No. of stations & $y$-intercept & Slope & $r^{2}$ & $\mathrm{p}$ \\
\hline 5104 & 8 & 52.2 & +0.046 & 0.048 & 0.25 \\
\hline 6404 & 12 & 56.3 & -0.004 & 0.0003 & 0.86 \\
\hline 7804 & 14 & 63.4 & -0.050 & 0.23 & $<0.0002$ \\
\hline 8303 & 13 & 70.9 & -0.043 & 0.106 & 0.004 \\
\hline 9504 & 13 & 67.9 & -0.089 & 0.228 & $<0.0002$ \\
\hline
\end{tabular}

Since PSI is determined mainly by the dominant species, it is necessary to look at those species to explain the anomalous years in PSI (Table 4). Metridia pacifica was unusually dominant in 1951 and unusually rare in the other 5 anomalous years. Calanus pacificus was unusually rare in all 6 anomalous years. Pleuromamma borealis was rare in 1951 and very abundant in 1983 and 1998. 'Other female calanoids' were very abundant in 1977 and Eucalanus californicus was the most abundant species in 1992. Each anomalous year generally showed a slightly different pattern of dominance, except 1983 and 1998, which were both characterized by low abundances of C. pacificus and M. pacifica, and dominance by $P$. borealis.

The mean of PSI values after the 1976/1977 climatic regime shift $(64.3 \%)$ was lower than the mean before $(72.5 \%)$. In addition, mean PSI between the 2 periods $(65.3 \%)$ was significantly lower than the mean within the periods $(68.2 \%, \mathrm{p}<0.0002)$. This difference does

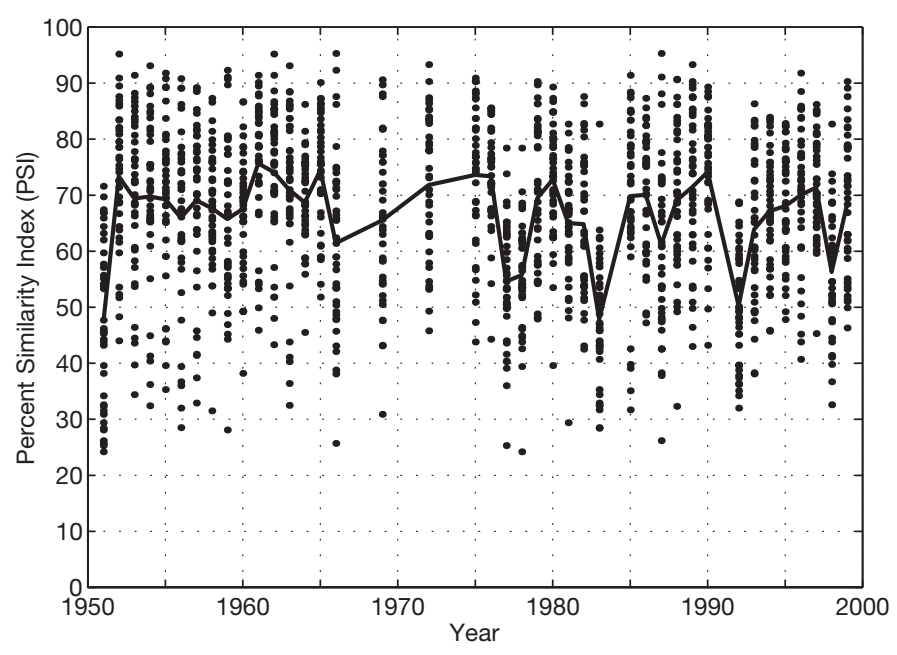

Fig. 6. Time series of PSI. Dots in each column represent comparisons between that year and every other year in the time series; e.g. dots in first column represent comparisons between the 1951 cruise and each of the other 40 cruises. Note that each pairwise comparison appears twice, once for each year in the pair. Continuous line connects mean values of PSI for each year 
Table 4. Percentages of the dominant categories for the spring cruises during the 6 anomalous years

\begin{tabular}{|lrrrrrrrc|}
\hline Category & 1951 & 1977 & 1978 & 1983 & 1992 & $1998 \begin{array}{c}\text { Overall mean of } \\
\text { 41 cruises }\end{array}$ \\
\hline Calanus pacificus & 7.4 & 20.0 & 24.9 & 9.3 & 4.3 & 13.9 & 33.9 \\
Metridia pacifica & 77.8 & 4.3 & 2.7 & 7.4 & 15.8 & 10.9 & 28.5 \\
Pleuromamma borealis & 4.6 & 21.4 & 17.3 & 51.0 & 19.9 & 36.8 & 14.6 \\
Eucalanus californicus & 3.5 & 11.0 & 15.0 & 4.7 & 25.5 & 8.2 & 4.5 \\
Other female calanoids & 2.7 & 23.0 & 12.0 & 9.8 & 12.0 & 11.0 & 7.0 \\
Sum & 96.0 & 79.7 & 71.9 & 82.2 & 77.5 & 80.8 & 88.5 \\
\hline
\end{tabular}

not seem to have been due to a large decline in the mean PSI for most years following the regime shift (see Fig. 6); if the 6 anomalous years are ignored, annual mean PSI values are similar before and after 1977. However, 5 of the 6 years with a mean PSI of less than $60 \%$ occurred in the latter period.

A number of atmospheric and oceanographic variables indicate that another regime shift may have occurred in the North Pacific in the late 1980s (Beamish et al. 1999, Brodeur et al. 1999, Overland et al. 1999). To determine if this event affected the species composition of calanoid copepods off southern California, a randomization test was done comparing the periods 1977 to 1988 and 1989 to 1999. No evidence was found for a difference between these 2 periods (mean PSI between periods $=64.4 \%$, mean PSI within periods $=$ $64.3 \%$ ). Similar results were obtained when a break between 1989 and 1990 was used.

The evidence for an effect of El Niño events on species composition is equivocal. Of the 4 strong El Niños identified from the coastal sea level record, 3 (1983, 1992 and 1998) were associated with anomalously low annual mean PSI values. However, the El Niño of 1958/1959 does not stand out in the PSI time series, and half of the anomalous cruises, 1951, 1977 and 1978, were not associated with strong California El Niños.

\section{DISCUSSION}

The species composition of calanoid copepods off southern California during spring appears to have been stable over the last half century, at least in terms of the dominant species. Except for a few anomalous years, the average percent similarity for each cruise (compared to all other cruises) was consistently high. Annual mean PSI returned to high values after each anomalous year (except for the 2 yr period of low PSI values in 1977/1978). The small decline in PSI as a function of time interval between cruises may be an artifact of the increase in sampling depth in 1969. The difference between the means of PSI before and after the 1976/1977 regime shift appears to be due to an increase in the frequency of perturbations rather than to a decrease in similarity between most cruises.

Is this evidence of stability in the calanoid copepod assemblage off southern California? Connell \& Sousa (1983) list several criteria for stability. First, a system that is perturbed must return to an equilibrium. Mean values of PSI returned to high values following each anomalous event (perturbation). Second, the time scale of observation must be greater than the generation time of the organisms, so that the entire assemblage turns over at least once during the study. The copepods in this study generally have generation times of less than 1 yr off southern California, much shorter than the $49 \mathrm{yr}$ covered by the study. Third, the spatial scale of the study must be appropriate. Assemblages are likely to appear unstable if the spatial scale is too small, but will always appear stable if the scale is too large, unless populations are increasing or decreasing globally. The population structure of zooplankton in the CCS is not well known. However, the pooled samples used in this study represent spatial averages for an area covering $\sim 71000 \mathrm{~km}^{2}$, but all of the species considered have distributions that extend far outside the study region (Fleminger 1964, 1967, Bowman \& Johnson 1973). It would appear, then, that this study meets Connell \& Sousa's criteria and does demonstrate stability in the calanoid copepod assemblage off southern California.

The conclusions of this study apply specifically to the dominant species. The rare species showed little consistency in rank order of abundance and contributed little to the PSI. The top 7 categories comprised on average approximately 95 of every 100 copepods counted. Little is known about the ecology of many of the rarer species, and some may have important functions in the planktonic ecosystem. However, most of the rare species are much more abundant outside the region and are probably relatively unimportant off southern California.

Given the advective nature of the CCS and the strong horizontal gradients in hydrographic properties, a high degree of stability might not be expected at an individual station. Samples taken years apart at a fixed location may not be from the same type of water mass and may contain very different assemblages. However, the limited number of stations analyzed individually suggest stability. Although similarities for the stations tend to be lower than for the pooled samples representing the entire study region, there was little decline over 
time for sampling intervals from 5 to $44 \mathrm{yr}$. Therefore, at a much smaller scale, that of a single station, there is still evidence for stability in the copepod species composition off southern California.

This long-term stability contrasts with changing environmental conditions in the CCS. Of particular note is a $70 \%$ decline in zooplankton biomass off southern California (Roemmich \& McGowan 1995a,b). Longterm stability in copepod species composition may be reconciled with the decline in zooplankton biomass in 2 ways: (1) there were no trends in density for the dominant species of copepods, (2) the dominant species declined in similar proportions. Trends for individual copepod species are being analyzed from the data set used in this study (Rebstock unpubl. data).

Of the 5 cruises for which stations were analyzed, 3 individually showed declines in PSI with increasing distance. Other investigators have also reported mixed results in similarity as a function of distance (Haury 1976, Mullin 1979, Star \& Mullin 1981). However, those studies used much shorter distances (up to about $10 \mathrm{~km}$ ) than the present study. The evidence of the present study suggests that over horizontal scales of a few hundred kilometers, similarity between samples tends to decrease with increasing distance. However, there is much scatter in the PSI values, and distance explains a maximum of about $23 \%$ of the variability. Cruises 5104 and 6404 did not show this decline. There may have been too few stations to detect a pattern in Cruise 5104; there was poor spatial coverage in Cruise 6404, with few stations in the northern and offshore parts of the study region.

The $y$-intercept values for the regression of PSI on distance might be expected to be close to the PSI values for replicate tows. However, the $y$-intercept values are lower, 52 to $71 \%$ (Table 3 ). This may be due to unresolved horizontal variability of copepod abundance at scales smaller than the standard CalCOFI station spacing $(\sim 37 \mathrm{~km})$. There may be a breakpoint in the curve at the smaller scales. For example, Star \& Mullin (1981) found a sharp drop in similarity between zooplankton samples from the California Current from the minimum distance measured $(<1 \mathrm{~km})$ to about $4 \mathrm{~km}$, then a leveling off of PSI to at least $10 \mathrm{~km}$.

The finding of stability in a planktonic assemblage in the CCS apparently contradicts the conclusions of McGowan and others. For example, Fig. 11 in McGowan \& Walker (1985) suggests little similarity in copepod species composition in the CCS in samples taken more than about $1 \mathrm{~d}$ apart. This figure shows PSI as a function of time interval during CalCOFI Cruise 5804 (April 1958). However, the time axis on that figure could be replaced by distance. The lowest PSI values are for comparisons between CalCOFI Line 80 (off Point Conception, California) and Line 100 (off
Ensenada, Baja California, Mexico). The highest values are for within-line comparisons. The decline in PSI with time over $8 \mathrm{~d}$ that McGowan \& Walker found can be explained, at least in part, by distance.

McGowan \& Walker (1985) did not address the issue of long-term stability in copepod assemblages in the CCS. Rather, they pointed out differences between the CCS and the North Pacific central gyre. The present study looked at the CCS on a slightly different spatial scale and a very different time scale. The different conclusions of the 2 studies probably result mainly from the difference in time scales, but they demonstrate the dangers of generalizing about a large and dynamic system such as the CCS.

In this study, perturbations were seen in the species composition in several years based on patterns of PSI. Large-scale climatic events are known to have affected the CCS on several time scales over the last half century. Two of these, climatic regime shifts and the ENSO cycle were investigated as potential disturbing forces. These events occur on appropriate time scales, interdecadal and interannual, for the PSI time series. A local indicator of El Niño was used because not all equatorial events affect higher latitudes to the same degree (e.g., Simpson 1984, McLain et al. 1985).

Years associated with low PSI values were more frequent after the 1976/1977 regime shift than before, suggesting that the regime shift may have influenced the frequency of perturbations. This may have been due in part to the strong El Niños of the 1980s and 1990s occurring during warmer background conditions than previous El Niños (e.g., Fedorov \& Philander 2000, see also Roemmich \& McGowan 1995a). The anomalous species composition seen during these El Niños was not due to a replacement of cool-water species by warm-water species. The dominant categories remained dominant, with shifts in rank among them (Table 4). No warm-water species was ever very abundant in this study.

Only half the anomalous years were associated with strong California El Niños. The 1977 and 1978 cruises both followed warm winters in the CCS. Winter 1976/1977 was characterized by warm conditions in the tropical Pacific (McLain et al. 1985, Trenberth 1997), but there was not a strong sea-level signal off southern California. However, a persistent high-pressure system over the western USA may have contributed to local ocean warming (McLain et al. 1985). The warm conditions off California in winter 1977/1978 were not coincident with a tropical El Niño (McLain et al. 1985). However, perturbations were seen in populations and species composition of other taxa in the CCS in 1978 (e.g., Brinton 1981, Ainley et al. 1995). The 1951 cruise remains unexplained. The species composition was unusual in that year, even among the other anomalous cruises. 
Sample timing and variable spatial coverage may bias results. Cruises occurred in March, April or May. In addition, the timing of seasonal events that may be important in zooplankton transport and dynamics, such as spring transition or phytoplankton blooms, vary among years (e.g., Thomas \& Strub 1989). However, the constancy of species composition argues against these sources of sampling error playing a major role in most years for the present study.

Large-scale climatic events seem to account for at least some of the perturbations in species composition in this system, but what mechanisms mediate the population responses to these events? Zooplankton biomass is correlated with southward transport in the CCS, but whether increases in biomass are due to responses of local populations to changing environmental conditions or direct advection of populations is not known (Chelton et al. 1982).

CalCOFI has measured chlorophyll and primary production since 1984. Hence, there are measurements of food availability over the study region during only 2 of the anomalous events. Integrated chlorophyll and primary production for April cruises in 1992 and 1998 fell within the range of values for 1984 to 1998 (Hayward et al. 1994, Lynn et al. 1998). Chlorophyll was also measured along 9 stations on Line 90 (Fig. 1A) in March and April 1983. There was little evidence for anomalies in chlorophyll during that period either (McGowan 1985). There is no evidence for bottom-up forcing during these 3 strong El Niño years; however, information on species composition of the phytoplankton is not yet available. Bottom-up forcing may be important if a shift to phytoplankton species representing a change in food quality occurred.

Copepods have many predators, both vertebrate and invertebrate. A full discussion of the possibilities of top-down forcing is beyond the scope of this paper. Top-down effects would depend on many factors, including spatial distribution of predators and prey and selectivity of feeding by predators, both of which might be affected by oceanographic conditions. Many warmwater species are known to extend their ranges northward into southern California waters during strong El Niños, while cold-water species may decline in the region. This interannual variability in predator populations and distributions occurs in addition to strong decadal-scale fluctuations in planktivorous fish stocks (MacCall 1996) and apparent trends in abundance of some gelatinous predators (Lavaniegos \& Ohman 1999). The effects on copepod populations would be very difficult to predict.

One may also turn the question around and ask what factors maintain the dominance structure in most years. Again, 2 possibilities are in situ biological interactions and steady advection of populations from other stable regions. The dominant species off southern California all have source regions to the north (Fleminger 1967, Mullin 1993, Ohman et al. 1998). If assemblages with constant species composition are advected from source regions, PSI values would tend to be high. However, the dominant species are known to have different life histories off southern California (Ohman et al. 1998), so it seems likely that processes besides advection maintain populations of at least some species. For example, part of the Calanus pacificus population overwinters as fifth-stage copepodites, which may be an important source of the next year's production (Osgood \& Checkley 1997).

PSI values from this study should not be compared with those of other studies because of the dependence of PSI on factors such as number of species, number of individuals, and equitability of abundances (Venrick 1983). In addition, use of the 'other female calanoids' category in this study reduced the total number of species considered, which increased the expected PSI (Venrick 1983). PSI would be further inflated if 2 samples contained different species in the 'other' category. For most comparisons, this inflated amount would be less than $6.1 \%$ (the median proportion of the 'other' category).

It should be noted that species composition herein refers to the assemblage that occupies a large volume of water and not necessarily to a community of co-occurring, interacting species. Samples pooled for a given cruise represent stations that are tens to hundreds of kilometers apart, certainly much farther than an individual copepod is able to swim horizontally in the ocean. Even at a given station, copepods that occupy different depths may be sampled in a single tow. These results should not be interpreted, then, to mean that an individual plankter would encounter the same copepod species over time. However, a larger, highly mobile organism might expect to find the same average species composition of calanoid copepods, at least in terms of the dominant species, in the southern California region of the CCS in spring of most years.

Acknowledgements. Samples were provided by the 'Pelagic Invertebrates Collection' of Scripps Institution of Oceanography. I thank Annie Townsend for prompt delivery of samples. Melissa Carter and Kirk Ireson did most of the sample preparation (pooling). I am very grateful to the crew and scientists who have collected and maintained the CalCOFI samples over the years. This manuscript was improved by comments from Dave Checkley, John McGowan, Mark Ohman, Trevor Price, Elizabeth Venrick and 4 anonymous reviewers. I was supported by graduate fellowships from the US Environmental Protection Agency (Science To Achieve Results) and Office of Naval Research. This is contribution number 181 of the US GLOBEC program, jointly funded by the National Science Foundation and the National Oceanic and Atmospheric Administration. This research was supported in part under NSF grant OCE-9711369. 


\section{LITERATURE CITED}

Ainley DG, Sydeman WJ, Norton J (1995) Upper trophic level predators indicate interannual negative and positive anomalies in the California Current food web. Mar Ecol Prog Ser 118:69-79

Beamish RJ, Noakes DJ, McFarlane GA, Klyashtorin L, Ivanov VV, Kurashov V (1999) The regime concept and natural trends in the production of Pacific salmon. Can J Fish Aquat Sci 56:516-526

Bowman TE, Johnson MW (1973) Distributional atlas of calanoid copepods in the California Current region, 1949 and 1950. CALCOFI Atlas 19:1-239

Brinton E (1981) Euphausiid distributions in the California Current during the warm winter-spring of $1977-78$, in the context of a 1949-66 time series. CALCOFI Rep 22:135-154

Brodeur RD, Mills CE, Overland JE, Walters GE, Schumacher JD (1999) Evidence for a substantial increase in gelatinous zooplankton in the Bering Sea, with possible links to climate change. Fish Oceanogr 8:296-306

Chelton DB, Bernal PA, McGowan JA (1982) Large-scale interannual physical and biological interaction in the California Current. J Mar Res 40:1095-1125

Connell JH, Sousa WP (1983) On the evidence needed to judge ecological stability or persistence. Am Nat 121:789-824

Conover RJ (1988) Comparative life histories in the genera Calanus and Neocalanus in high latitudes of the northern hemisphere. Hydrobiologia 167/168:127-142

CPR Survey Team (1992) Continuous plankton records: the North Sea in the 1980s. ICES Mar Sci Symp 195:243-248

Ebbesmeyer CC, Cayan DR, McLain DR, Nichols FH, Peterson DH, Redmond KT (1991) 1976 step in the Pacific climate: forty environmental changes between 1968-1975 and 1977-1984. In: Betancourt JL, Thorp VL (eds) Proceedings of the Seventh Annual Pacific Climate (PACLIM) Workshop, 1990, Interagency Ecological Studies Program Technical Report, Vol 26. California Department of Water Resources, Sacramento, CA, p 115-126

Fedorov AV, Philander SG (2000) Is El Niño changing? Science 288:1997-2002

Fleminger A (1964) Distributional atlas of calanoid copepods in the California Current Region, Part I. CALCOFI Atlas $2: 1-313$

Fleminger A (1967) Distributional atlas of calanoid copepods in the California Current Region. Part II. CALCOFI Atlas $7: 1-213$

Floder S, Sommer U (1999) Diversity in planktonic communities: an experimental test of the intermediate disturbance hypothesis. Limnol Oceanogr 44:1114-1119

Haury LR (1976) A comparison of zooplankton patterns in the California Current and North Pacific Central Gyre. Mar Biol 37:159-167

Hayward TL, Mantyla AW, Lynn RJ, Smith PE, Chereskin TK (1994) The state of the California Current in 1993-1994. CALCOFI Rep 35:19-35

Kramer D, Kalin MJ, Stevens EG, Thrailkill JR, Zweifel JR (1972) Collecting and processing data on fish eggs and larvae in the California Current region. NMFS CIRC-370, National Oceanic and Atmospheric Administration, US Department of Commerce, Seattle

Lavaniegos BE, Ohman MD (1999) Hyperiid amphipods as indicators of climate change in the California Current. In: Schram FR, von Vaupel Klein JC (eds) Proceedings of the Fourth International Crustacean Congress, Amsterdam, The Netherlands, 1998, Vol 1. Brill, Boston, p 489-509

Lenarz WH, Ventresca DA, Graham WM, Schwing FB, Chavez F (1995) Explorations of El Niño events and associated biological population dynamics off central California. CALCOFI Rep 36:106-119

Lindley JA, Gamble JC, Hunt HG (1995) A change in the zooplankton of the central North Sea $\left(55^{\circ}\right.$ to $\left.58^{\circ} \mathrm{N}\right)$ : a possible consequence of changes in the benthos. Mar Ecol Prog Ser 119:299-303

Lynn RJ, Baumgartner T, Garcia J, Collins CA, Hayward TL, Hyrenbach KD, Mantyla AW, Murphree T, Shankle A, Schwing FB, Sakuma KM, Tegner MJ (1998) The state of the California Current, 1997-1998: Transition to El Niño conditions. CALCOFI Rep 39:25-49

MacCall AD (1996) Patterns of low-frequency variability in fish populations of the California Current. CALCOFI Rep 37:100-110

McGowan JA (1985) El Niño 1983 in the southern California Bight. In: Wooster WS, Fluharty DL (eds) El Niño north: Niño effects in the eastern subarctic Pacific Ocean. Washington Sea Grant Program, Seattle, p 166-184

McGowan JA (1990) Species dominance-diversity patterns in oceanic communities. In: Woodwell GM (ed) The Earth in transition. Patterns and processes of biotic impoverishment. Cambridge University Press, Cambridge, p 395-421

McGowan JA, Brown DM (1966) A new opening-closing paired zooplankton net. Scripps Institution of Oceanography, University of California, La Jolla (SIO Ref 66-23)

McGowan JA, Walker P (1985) Dominance and diversity maintenance in an oceanic ecosystem. Ecol Monogr 55:103-118

McLain DR, Brainard RE, Norton JG (1985) Anomalous warm events in eastern boundary current systems. CALCOFI Rep 26:51-64

Miller AJ, Cayan DR, Barnett TP, Graham NE, Oberhuber JM (1994a) The 1976-77 climate shift of the Pacific Ocean. Oceanography 7:21-26

Miller AJ, Cayan DR, Barnett TP, Graham NE, Oberhuber JM (1994b) Interdecadal variability of the Pacific Ocean: model response to observed heat flux and wind stress anomalies. Climate Dynamics 9:287-302

Miller CB, Batchelder HP, Brodeur RD, Pearcy WG (1985) Response of the zooplankton and ichthyoplankton off Oregon to the El Niño event of 1983. In: Wooster WS, Fluharty DL (eds) El Niño North: Niño effects in the eastern subarctic Pacific Ocean. Washington Sea Grant Program, Seattle, p 185-187

Minobe S, Mantua N (1999) Interdecadal modulation of interannual atmospheric and oceanic variability over the North Pacific. Prog Oceanogr 43:163-192

Moser HG, Smith PE (1993) Larval fish assemblages of the California Current region and their horizontal and vertical distributions across a front. Bull Mar Sci 53:645-691

Mullin MM (1979) Longshore variation in the distribution of plankton in the Southern California Bight. CALCOFI Rep 20:120-124

Mullin MM (1993) Reproduction by the oceanic copepod Rhincalanus nasutus off southern California, compared to that of Calanus pacificus. CALCOFI Rep 34:89-103

Mullin MM (1998) Interannual and interdecadal variation in California Current zooplankton: Calanus in the late 1950s and early 1990s. Glob Change Biol 4:115-119

Murphree T, Reynolds C (1995) El Niño and La Niña effects on the northeast Pacific: The 1991-1993 and 1988-1989 events. CALCOFI Rep 36:45-56

Ohman MD, Smith PE (1995) A comparison of zooplankton sampling methods in the CALCOFI time series. CALCOFI Rep 36:153-158

Ohman MD, Drits AV, Clarke ME, Plourde S (1998) Differential dormancy of co-occurring copepods. Deep-Sea Res II 45:1709-1740 
Osgood KE, Checkley DM Jr (1997) Observations of a deep aggregation of Calanus pacificus in the Santa Barbara Basin. Limnol Oceanogr 42:997-1001

Overland JE, Adams JM, Bond NA (1999) Decadal variability of the Aleutian low and its relation to high-latitude circulation. J Climate 12:1542-1548

Palomares-Garcia R, Gomez-Gutierrez J (1996) Copepod community structure at Bahia Magdalena, Mexico during El Niño 1983-84. Estuar Coast Shelf Sci 43:583-595

Rebstock GA (2001) An analysis of a zooplankton samplinggear change in the CALCOFI long-term monitoring program, with implications for copepod population abundance trends. Prog Oceanogr (in press)

Reid PC (1975) Large scale changes in North Sea phytoplankton. Nature 257:217-219

Reid PC (1977) Continuous plankton records: changes in the composition and abundance of the phytoplankton of the north-eastern Atlantic Ocean and North Sea, 1958-1974. Mar Biol 40:337-339

Roemmich D, McGowan JA (1995a) Climatic warming and the decline of zooplankton in the California Current. Science 267:1324-1326

Roemmich D, McGowan JA (1995b) Sampling zooplankton: correction. Science 268:352-353

Roesler CS, Chelton DB (1987) Zooplankton variability in the California Current, 1951-1982. CALCOFI Rep 28:59-96

Sherman K, Green JR, Goulet JR, Ejsymont L (1983) Coherence in zooplankton of a large northwest Atlantic ecosystem. Fish Bull 81:855-862

Simpson JJ (1984) Warm and cold episodes in the California Current: a case for large-scale mid-latitude atmospheric forcing. In: Proceedings of the Ninth Annual Climate Diagnostics Workshop, Department of Atmospheric Sci-

Editorial responsibility: Otto Kinne (Editor),

Oldendorf/Luhe, Germany ences, Oregon State University, 1984, National Oceanic and Atmospheric Administration. US Department of Commerce, p 173-184

Smith PE (1985) A case history of an anti-El Niño to El Niño transition on plankton and nekton distribution and abundances. In: Wooster WS, Fluharty DL (eds) El Niño North: Niño effects in the eastern subarctic Pacific Ocean. Washington Sea Grant Program, Seattle, p 121-142

Southward AJ (1980) The western English Channel-an inconstant ecosystem? Nature 285:361-366

Star JL, Mullin MM (1981) Zooplankton assemblages in three areas of the North Pacific as revealed by continuous horizontal transects. Deep-Sea Res 28A:1303-1322

Thomas AC, Strub PT (1989) Interannual variability in phytoplankton pigment distribution during the spring transition along the west coast of North America. J Geophys Res 94: 18095-18117

Trenberth KE (1997) The definition of El Niño. Bull Am Meteorol Soc 78:2771-2777

Valdes L, Moral M (1998) Time-series analysis of copepod diversity and species richness in the southern Bay of Biscay off Santander, Spain, in relation to environmental conditions. ICES J Mar Sci 55:783-792

Venrick EL (1983) Percent similarity: the prediction of bias. Fish Bull 81:375-387

Venrick EL (1990) Phytoplankton in an oligotrophic ocean: species structure and interannual variability. Ecology 71: 1547-1563

Whittaker RH (1952) A study of summer foliage insect communities in the Great Smoky Mountains. Ecol Monogr 22:1-44

Whittaker RH, Fairbanks CW (1958) A study of plankton copepod communities in the Columbia Basin, southeastern Washington. Ecology 39:46-65

Submitted: July 28, 2000; Accepted: October 13, 2000 Proofs received from author(s): May 2, 2001 